\title{
Environmental Enrichment Mitigates Cognitive Deficits in a Mouse Model of Alzheimer's Disease
}

\author{
Joanna L. Jankowsky, ${ }^{1}$ Tatiana Melnikova, ${ }^{1,2}$ Daniel J. Fadale, ${ }^{4}$ Guilian M. Xu, ${ }^{1}$ Hilda H. Slunt, ${ }^{1}$ Victoria Gonzales, ${ }^{1}$ \\ Linda H. Younkin, ${ }^{4}$ Steven G. Younkin, ${ }^{4}$ David R. Borchelt, ${ }^{1,3}$ and Alena V. Savonenko ${ }^{1,2}$ \\ Departments of ${ }^{1}$ Pathology, ${ }^{2}$ Neurology, and ${ }^{3}$ Neuroscience, The Johns Hopkins University School of Medicine, Baltimore, Maryland 21205, and ${ }^{4}$ Mayo \\ Clinic Jacksonville, Jacksonville, Florida 32224
}

Epidemiological studies suggest that individuals with greater education or more cognitively demanding occupations have diminished risk of developing dementia. We wanted to test whether this effect could be recapitulated in rodents using environmental enrichment, a paradigm well documented to attenuate behavioral deficits induced by various pathological insults. Here, we demonstrate that learning and memory deficits observed in a transgenic mouse model of Alzheimer's disease can be ameliorated by enrichment. Female transgenic mice overexpressing amyloid precursor protein and/or presenilin-1 and nontransgenic controls were placed into enriched or standard cages at 2 months of age and tested for cognitive behavior after 6 months of differential housing. Enrichment significantly improved performance of all genotypes in the radial water maze and in the classic and repeated-reversal versions of the Morris water maze. However, enrichment did not benefit all genotypes equally. Mice overproducing amyloid- $\beta(\mathrm{A} \beta)$, particularly those with amyloid deposits, showed weaker memory for the platform location in the classic Morris water maze and learned new platform positions in the repeated-reversals task less quickly than their nontransgenic cagemates. Nonetheless, enrichment normalized the performance of $\mathrm{A} \beta$ overproducing mice to the level of standard-housed nontransgenic mice. Moreover, this functional preservation occurred despite increased neuritic plaque burden in the hippocampus of double-transgenic animals and elevated steady-state $A \beta$ levels, because both endogenous and transgene-derived $\mathrm{A} \beta$ are increased in enriched animals. These results demonstrate that the generation of $\mathrm{A} \beta$ in vivo and its impact on the function of the nervous system can be strongly modulated by environmental factors.

Key words: Alzheimer's disease; transgenic mouse; amyloid precursor protein; A $\beta$; environmental enrichment; cognitive behavior

\section{Introduction}

In the 17 years since Mortimer (1988) first predicted a link between education and dementia, over a dozen epidemiological studies have examined the evidence for this hypothesis in populations from across the globe (for review, see Katzman, 1993; Friedland, 1994; Mortimer, 1997; Terry et al., 1999). Although not universal, the majority of these studies have found that lack of

Received Dec. 13, 2004; revised April 14, 2005; accepted April 17, 2005.

This work was supported by grants from the National Institutes of Health (AG06656 and AG15453 to S.G.Y. and K01AG26144 to J.L.J.) the John Douglas French Alzheimer's Foundation (J.L.J.), and the American Health Assistance Foundation (J.L.J.). We thank Henriette van Praag and Fred Gage for kindly donating the enrichment cages; Malcolm Leissring, Dennis Selkoe, and Eddie Koo for generously providing IDE-1 and CT15 antibodies; Gay Rudow for help with stereology; Marshall White for animal care; Irene Chang, Allegra Heinrichs, Julia Hsiao, Johanna Morton, Seung-Hyun Woo, Daniel Lamphier, Marco Boccitto, Kimberly Townsend, and Linda Trinh for animal handling and help with behavioral testing; Andres Collazo for assistance with confocal microscopy; and Andy Groves for helpful discussions. We also thank several anonymous reviewers for thoughtful comments that helped us improve this manuscript. We gratefully acknowledge Takeda Chemical Industries Company, Ltd. for providing antibodies BAN50, BNT77, BA27, and BC05. J.L.J. thanks Eloise Goodhew Barnett for her continued support of this research. We regret that, because of space limitations, we were unable to include citations for many of the original articles on both animal enrichment and human epidemiology. We have attempted to reference the earliest or most significant primary publications followed by review articles in which additional studies are discussed.

Correspondence should be addressed to Dr. Joanna L. Jankowsky, Division of Biology, Mail Code 156-29, California Institute of Technology, Pasadena, CA 91125. E-mail: jij2@caltech.edu.

D. R. Borchelt's present address: Department of Neuroscience, McKnight Brain Institute, University of Florida, Gainesville, FL 32610 .

D0I:10.1523/JNEUROSCI.5080-04.2005

Copyright $\odot 2005$ Society for Neuroscience $\quad 0270-6474 / 05 / 255217-08 \$ 15.00 / 0$ education is a major risk factor for Alzheimer's disease (Zhang et al., 1990; Friedland, 1993; Stern et al., 1994; White et al., 1994). Other lifestyle choices, including occupation, leisure activities, and physical exercise, may also modulate the risk of cognitive decline (Stern et al., 1994; Bonaiuto et al., 1995; Friedland et al., 2001) (for review, see Pope et al., 2003; Fratiglioni et al., 2004; Scarmeas and Stern, 2004). These findings have fostered the concept of cognitive reserve as a defense against dementia (Katzman, 1993; Stern, 2002). This hypothesis posits that people with more mental activity develop stronger, better elaborated neuronal connections that can withstand a greater amount of pathological damage before succumbing to disease. Recent advances in imaging techniques suggest that elderly patients with maintained cognitive function recruit new areas of their brains for memory tasks, finding new strategies to recall old information (for review, see Buckner, 2004). Thus, both passive retention of preexisting connections and the active use of new retrieval networks may contribute to the prevention of dementia through cognitive reserve (Stern, 2002).

The cognitive-reserve hypothesis is consistent with several decades of research on environmental manipulation in rodents. Rodents housed in enriched cages with access to novel objects, exercise wheels, and increased social interaction with a large number of cagemates show significant changes in brain biochemistry, synaptic morphology, and neuronal function compared 
with standard-housed animals (for review, see van Praag et al., 2000). These changes likely provide the groundwork for numerous cognitive improvements after enrichment. Enriched housing improves performance in a variety of behavioral tasks, including two-way active avoidance (Escorihuela et al., 1994), contextual conditioning (Rampon et al., 2000; Woodcock and Richardson, 2000; Duffy et al., 2001), and delayed alternation (Winocur and Greenwood, 1999). Perhaps the best-studied improvements occur in the Morris water maze (MWM), a test of hippocampaldependent spatial learning (Saari et al., 1990; Park et al., 1992; Wainwright et al., 1993) (for review, see van Praag et al., 2000). Mice housed in enriched environments learn the location of a hidden platform faster than standard-housed controls and spend more time searching the correct part of the maze when the platform is removed for probe trials. These findings suggest that environmental enrichment can dramatically influence learning and memory, improving both acquisition and retention of new tasks.

We wanted to explore whether environmental enrichment would be equally beneficial in a setting of Alzheimer's-associated neuropathology. In a previous study, we observed that enriched transgenic mice coexpressing the Swedish variant of amyloid precursor protein (APPswe) and the exon-9 deleted variant of presenilin 1 (PS1dE9) tended to develop more amyloid than standard-housed controls (Jankowsky et al., 2003). However, the hybrid $\mathrm{C} 3 \mathrm{HeJ} \times \mathrm{C} 57 \mathrm{BL} / 6$ background of this original cohort precluded analysis of cognitive behavior (Banbury Conference on Genetic Background in Mice, 1997). We therefore began a new study using APPswe and PS1dE9 lines that had been backcrossed to C57BL/6J for $>10$ generations, making them nearly identical at all but the transgenic loci. As seen in several other APP transgenic lines (for review, see Janus and Westaway, 2001; Dodart et al., 2002; Higgins and Jacobsen, 2003), we find that under standard housing conditions, our APPswe and APPswe/PS1dE9 mice also show cognitive deficits in several hippocampal-dependent spatial memory tasks. We demonstrate here that these deficits are prevented by environmental enrichment. Consistent with the recent in vitro demonstration that synaptic activity increases the production of amyloid- $\beta(\mathrm{A} \beta)$ and soluble APP derivatives (Nitsch et al., 1993; Kamenetz et al., 2003), we find that mice provided with environmental stimulation harbor higher levels of $\mathrm{A} \beta 42$ than their standard-housed counterparts. Together, these findings provide experimental evidence for the cognitive-reserve hypothesis and demonstrate that environmental factors can strongly modulate the impact of $\mathrm{A} \beta$ on cognitive performance.

\section{Materials and Methods}

Transgenic mice. Two lines of transgenic mice were used for this study. Line C3-3 expresses chimeric mouse APP with the Swedish mutation K670N/M671L and a humanized A $\beta$ domain (Borchelt et al., 1996, 1997). Line S-9 expresses the exon-9 deleted variant of human PS1 (Lee et al., 1997; Jankowsky et al., 2004). Both transgenes are active in the CNS under the control of the mouse prion protein promoter. Before this study, each line was backcrossed for 9-11 generations to be congenic on the C57BL/6J background (The Jackson Laboratory, Bar Harbor, ME). Animals for this study were generated from a final backcross of doubletransgenic C3-3 APPswe B6n11/S-9 PS1dE9 B6n9 males with nontransgenic (NTg) C57BL/6J females to yield B6n10 offspring.

Environmental enrichment. Seventy-six female mice derived from lines C3-3 and S-9 (as described above) were used for this study. At $\sim 2$ months of age, 32 of the animals were placed into two large $\left(1 \mathrm{~m}^{2}\right)$ enrichment cages (four NTg, four APP, four PS1, and four APP/PS1 per cage). The animals in each cage were age matched and comprised a single group throughout the experiment. Thus, there were no alterations to the social cohort for the duration of the experiment. The enrichment cages housing these animals had been used previously by van Praag et al. (1999) in their studies of enrichment-associated hippocampal neurogenesis and were kindly shared with us for these experiments. The enrichment cages provided $\sim 625 \mathrm{~cm}^{2}$ of floor space for each animal, more than three times that available for each control animal housed in standard colony cages. The enrichment cages contained two running wheels, plastic play tubes, cardboard boxes, and nesting material that were changed or rearranged weekly to provide novel stimulation. This setting provided our animals with the classic form of environmental enrichment used for several decades to study neuroanatomical and behavioral changes associated with cognitive stimulation (for review, see van Praag et al., 2000).

Age-matched control animals were housed three to four per cage in standard cages $\left[\sim 600 \mathrm{~cm}^{2}\left(150-200 \mathrm{~cm}^{2}\right.\right.$ per animal $\left.)\right]$ containing only pine chip bedding. Where possible, siblings were divided equally between enriched and control cohorts. Both enriched and control mice were housed in the same room on a 14/10 h light/dark cycle. All mice were provided fresh food and water ad libitum. Animal protocols were approved by The Johns Hopkins University Institutional Animal Care and Use Committee.

Behavioral testing. Behavioral testing began after 6 months of differential housing, when the mice were $\sim 8$ months of age. Throughout the testing period, animals were returned to their home cage at the end of the session each day. Before cognitive testing, mice were handled for $5 \mathrm{~d}$, and their basic visual ability was confirmed by retreat from placement on a horizontal edge. Mice were then pretrained in a small pool $(50 \mathrm{~cm}$ in diameter) to use a submerged platform $(10 \times 10 \mathrm{~cm})$ for escape from the water. Swimming ability was assessed using a straight water alley $(12 \times$ $120 \mathrm{~cm}$ ) containing a submerged platform; no significant differences in latency were observed between housing conditions or genotypes. After pretraining, all cognitive tests were conducted in a 100-cm-diameter tank filled with opaque water $\left(21 \pm 2^{\circ} \mathrm{C}\right)$ and surrounded by proximal and distal visual cues. Testing began with a version of the standard MWM task in which mice were required to find a hidden platform that remained in the center of one quadrant for $5 \mathrm{~d}$ of testing (Andreasson et al., 2001). Each day, mice were given 10 training trials, in which the platform was submerged but accessible, and two probe trials (one before and one after the training session), in which the platform was completely submerged and inaccessible for variable intervals (30-40 s). At the end of each probe trial, the platform was returned to its raised position to maintain response-reinforcement contingency (Markowska et al., 1993). After $5 \mathrm{~d}$ of classic MWM, three repeated-reversal sessions were performed that used the same training and testing schedules as the MWM, but in which the platform location was changed daily. After completing the last reversal session, $5 \mathrm{~d}$ of radial water maze testing were conducted using the same pool and spatial cues (Arendash et al., 2001). Finally, visual abilities were analyzed more vigorously by marking the platform location with a highcontrast extension, enclosing the pool with black curtains and then measuring the distance swam to the platform in 10 trials per animal (Savonenko et al., 2003). No genotype-related differences in visual discrimination were detected in mice of either housing condition. Performance in all tasks was recorded by a computer-based video tracking system (HVS Image Analysis VP-200; HVS Image, Hampton, UK). Data were analyzed off-line using HVS Image and Microsoft Excel software.

Stereology. Ten days after behavioral testing was complete, animals were anesthetized and killed by decapitation. The brains were removed into ice-cold PBS and dissected. One-half of each brain was fixed and prepared for histology. Neuritic plaques were labeled by ubiquitin immunohistochemistry as described previously (Jankowsky et al., 2003). StereoInvestigator software (MicroBrightField, Colchester, VT) was used to define the dorsal hippocampal formation and estimate the surface area covered by plaques using an area-fractionator grid (Cavalieri spacing, $250 \times 250 \mu \mathrm{m}$; grid spacing, $15 \mu \mathrm{m}$; frame size, $90 \times 125 \mu \mathrm{m}$; $40 \times$ magnification). The percentage of coverage in three sections taken from the lateral, middle, and medial hippocampus was averaged to obtain a final estimate of plaque burden in each animal.

A $\beta$ ELISA. Hippocampal tissue from the remaining hemisphere was sonicated in $70 \%$ formic acid and centrifuged, and the supernatant was recovered for A $\beta$ ELISA as described previously (Kawarabayashi et al., 
Morris Water Maze

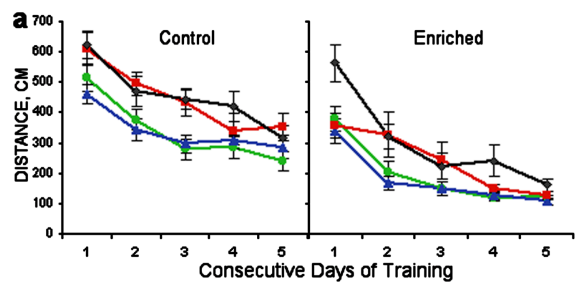

Repe a ted

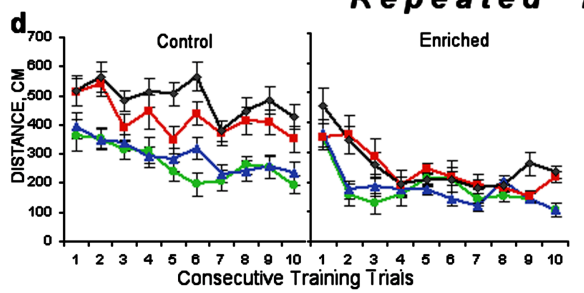

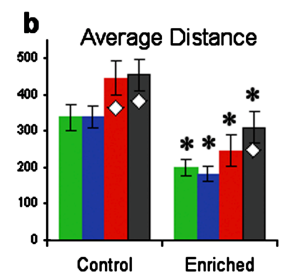

Reversals
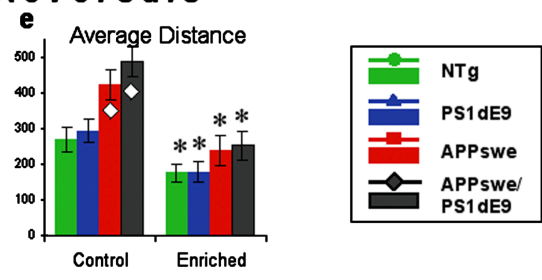

Contol
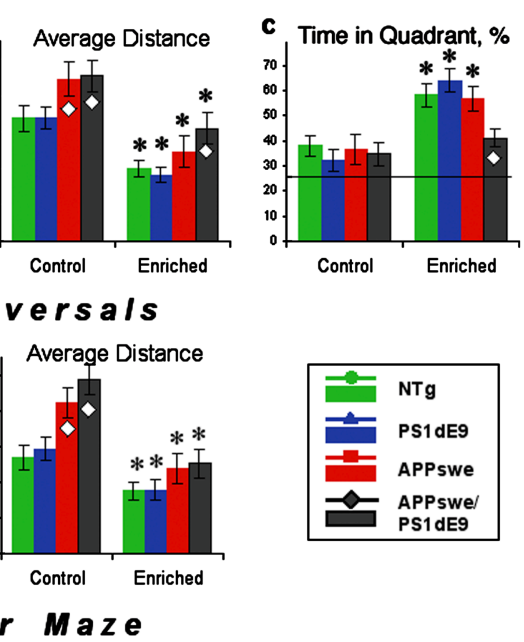

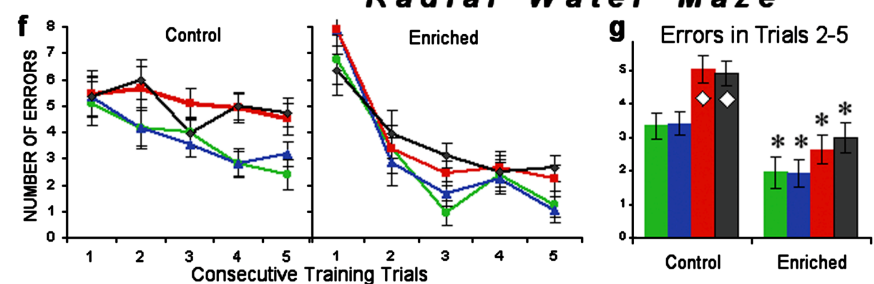

Figure 1. Enrichment attenuates cognitive deficits in APP and APP/PS1 mice. $\boldsymbol{a}-\boldsymbol{c}$, Classic MWM. $\boldsymbol{a}$, Mean distance traveled in consecutive days of training (average of 10 trials per day $\pm S E M$ ). Genotype-related differences were significant in both the standard-housed [two-way (genotype by day) ANOVA; $F_{(3,37)}=5.40 ; p<0.004$ ] and enriched $\left(F_{(3,27)}=6.78 ; p<0.002\right)$ groups and decreased as training progressed (genotype-by-day interaction; $p<0.05$ ). $\boldsymbol{b}$, Average distance to find the platform for $5 \mathrm{~d}$ of testing. Enrichment decreased the path length of all genotypes [two-way (enrichment by genotype) ANOVA; enrichment: $F_{(1,64)}=72.89, p<0.0001$; genotype: $\left.F_{(3,64)}=10.17, p<0.0002\right]$.c, Percentage of time in the correct quadrant during the final probe trial (day 5). Enrichment improved memory in all but APPswe/PS1dE9 mice (enrichment: $F_{(1,64)}=32.28, p<0.0001$; genotype-by-enrichment interaction: $F_{(3,64)}=3.44, p<0.02$ ). The horizontal line indicates the chance level of performance. $\boldsymbol{d}$, $\boldsymbol{e}$, Repeated-reversal training. $\boldsymbol{d}$, Mean distance swam in consecutive training trials averaged across three sessions. The standardhoused APPswe and APPswe/PS1dE9 groups remained impaired throughout training [two-way (genotype by trial) ANOVA; genotype: $F_{(3,37)}=10.24, p<0.0001$; trial: $\left.F_{(9,333)}=4.87, p<0.0001\right]$. In contrast, the performance of the enriched APPswe and APPswe/PS1dE9 groups improved with consecutive trials, reaching levels comparable with the NTg and PS1dE9 groups (trial: $F_{(9,243)}=11.42, p<0.0001$; genotype-by-trial interaction: $\left.F_{(24,216)}=2.53, p<0.02\right) . e$, Average distance to find the platform over training trials $2-10$ of three reversal sessions. Enrichment improved performance in all genotypes (enrichment: $F_{(1,64)}=$ 55.04, $p<0.0001$; genotype: $\left.F_{(3,64)}=11.49, p<0.0001\right)$. Simple main-effect ANOVA confirmed deficits in standard-housed $(p<0.001)$ but not enriched ( $p>0.3)$ APPswe and APPswe/PS1dE9 mice. $\boldsymbol{f}, \boldsymbol{g}$, Six-arm radial water maze. $\boldsymbol{f}$, Number of errors (incorrect arm entries) averaged by trial over $5 \mathrm{~d}$ of testing. Performance improved significantly with training for both housing conditions (trial: $F=4.21-5.52 ; p<0.002$ ). Standard-housed but not enriched APPswe and APPswe/PS1dE9 groups were significantly impaired compared with the $\operatorname{NTg}$ group $\left(F_{(3,37)}=4.89 ; p<0.006\right)$. g, Average number of errors during training trials $2-5$ over $5 \mathrm{~d}$ of testing. Enrichment improved performance in all groups (enrichment: $F_{(1,64)}=39.29, p<0.0001$; genotype: $\left.F_{(3,64)}=6.28, p<0.02\right)$. Simple main-effect ANOVA confirmed impairments in standard-housed $(p<0.006)$ but not enriched APPswe and APPswe/PS1dE9 mice. Asterisks indicate a significant difference between enriched and standard-housed groups of the same genotype (ANOVA; $p<0.01$ ). Diamonds indicate a significant difference from NTg mice of the same housing condition (Newman-Keuls post hoc test; $p<0.01$ applied to significant effect of genotype in the simple main-effect ANOVA). Error bars represent mean \pm SEM.

2001). Human $A \beta$ was measured in APP and APP/PS1 transgenic mice using BAN50 for capture (epitope $\mathrm{A} \beta 1-16)$ and BA27 and BC05 for detection ( $A \beta 40$ and $A \beta 42$, respectively); mouse $A \beta$ in NTg animals was quantified using BNT77 (epitope A $\beta 11-28$ ) for capture and BA27 or $\mathrm{BC} 05$ for detection. All values were calculated as picomoles per gram based on the initial weight of hippocampal tissue.

Histology and immunocytochemistry. Detailed methods for Hirano silver stain and ubiquitin immunocytochemistry were described by Jankowsky et al. (2003). Anti-A $\beta$ immunostaining was performed as described for ubiquitin, using monoclonal antibody 4G8 (Signet Laboratories, Dedham, MA) at a 1:250 dilution.

Statistical analyses. Statistical significance for data from stereology was evaluated by Student's $t$ test assuming equal variances and by two-sample $F$ test for variance (Microsoft Excel). Multi-group behavioral data and

$\mathrm{A} \beta$ ELISA were evaluated by ANOVA with the Newman-Keuls post hoc test applied to significant main effects or interactions (Statistica 6.0; StatSoft, Tulsa OK).

\section{Results}

Enrichment mitigates cognitive decline in female APPswe and APPswe/PS1dE9 mice

Many different enrichment paradigms have been described in the literature, ranging from the simple introduction of novel objects into standard cages (van Dellen et al., 2000) to the complex social cohort housed in large cages outfitted with hiding tubes and running wheels (Kempermann et al., 1997; van Praag et al., 1999). In the present study, we used the latter paradigm, in which 16 mice were housed together from weaning age to adulthood and were provided throughout with social interaction, novel objects, nesting material, and exercise wheels. Enrichment of this type has been demonstrated to improve the performance of healthy, wild-type rodents in multiple tests of learning and memory (for review, see van Praag et al., 2000). This paradigm required that we focus on female mice, because aggression between males would result in fighting, wounding, and chronic stress.

The two transgenic lines used for this study, C3-3 (APPswe) and S-9 (PS1dE9), were characterized initially on a hybrid background for study of neuropathology and were then made congenic on a C57BL/6 background for behavioral analysis (Banbury Conference on Genetic Background in Mice, 1997). All four genotypes derived from APPswe $\times$ PS1dE9 matings were analyzed so that we could control for the effects of each transgene in animals lacking amyloid in addition to examining the effects of enrichment in animals with fulminant plaque pathology. After ensuring visual and motor skills were intact, the mice were tested in a series of water maze tasks [classic MWM (Morris, 1984; Frick et al., 1995), repeatedreversal MWM (Chen et al., 2000; Morris, 2001), and radial water maze (Morgan et al., 2000)] designed to assess spatial learning and long-term memory of a fixed location, as well as the ability to modify that memory when the escape location was changed.

Analysis of behavioral testing demonstrates that overexpression of APPswe alone or in combination with the PS1dE9 transgene leads to significant impairment of hippocampal-dependent learning and memory in standard-housed transgenic mice (Fig. $1 a, d, f$ ) (ANOVAs; effect of genotype: $F_{(3,37)}=4.89-10.24 ; p<$ $0.01)$. Female APPswe single-transgenic mice swam significantly greater distances (Newman-Keuls post hoc test applied to significant effect of genotype; $p<0.01$ in the standard MWM and the 
repeated-reversal tasks) and made more errors locating the hidden platform (Newman-Keuls post hoc test; $p<0.005$ in the radial water maze) than did PS1dE9 or NTg mice. These impairments appeared long before the onset of amyloid pathology in APPswe single-transgenic animals. Female APPswe/PS1dE9 double-transgenic mice, which have substantial amyloid deposition and much higher levels of $\mathrm{A} \beta$, were similarly impaired by measures of swim path length (Newman-Keuls post hoc test; $p<$ 0.005 in the standard MWM and the repeated-reversal tasks) and incorrect arm entry (Newman-Keuls post hoc test; $p<0.01$ in the radial water maze).

As expected, enrichment significantly improved cognitive performance in NTg animals. In the MWM, enriched NTg mice swam shorter distances to reach the hidden platform than their nonenriched counterparts (ANOVA; effect of enrichment: $F_{(1,14)}=35.21 ; p<0.0001$ ) (Fig. $1 a, b$ ) and spent considerably more time in the trained quadrant when the platform was removed for probe retention trials $\left(F_{(1,14)}=10.84 ; p<0.01\right)$ (Fig. $1 c)$. On repeated-reversal testing, swim path was again shortened $\left(F_{(1,14)}=6.47 ; p<0.025\right)$ (Fig. $\left.1 d, e\right)$, and incorrect arm entries were reduced in the radial water maze $\left(F_{(1,14)}=14.44 ; p<0.002\right)$ (Fig. 1 $f, g$ ) compared with standard-housed NTg mice. Performance of single transgenic PS1dE9 mice was similarly improved by enrichment, with shorter path lengths $\left(F_{(1,16)}=12.40-38.72\right.$; $p<0.005$ in the standard MWM and the repeated-reversal tasks) (Fig. 1b,e), higher preference for the correct quadrant $\left(F_{(1,16)}=\right.$ 24.66; $p<0.0001)$ (Fig. 1c), and fewer errors $\left(F_{(1,16)}=9.77 ; p<\right.$ 0.01 in the radial water maze) (Fig. $1 g$ ) than standard-housed PS1dE9 animals.

Both APPswe and APPswe/PS1dE9 mice also benefited from enrichment. Compared with standard-housed mice of the same genotype, enriched APPswe and APPswe/PS1dE9 mice swam shorter distances to the hidden platform in the MWM (ANOVA; APPswe: $F_{(1,17)}=18.63, p<0.001$; APPswe/PS1dE9: $F_{(1,17)}=$ 10.90, $p<0.005$ ) (Fig. $1 a, b)$ and repeated reversals (APPswe: $F_{(1,17)}=22.56, p<0.0002$; APPswe/PS1dE9: $F_{(1,17)}=18.63, p<$ 0.0005 ) (Fig. $1 d, e$ ) and made fewer errors in the radial water maze (APPswe: $F_{(1,17)}=8.86, p<0.01$; APPswe/PS1dE9: $F_{(1,17)}=7.82$, $p<0.01$ ) (Fig. $1 f, g$ ).

Although mice of all genotypes benefited from enrichment, animals overproducing APP did not always attain the same level of performance as their NTg and PS1dE9 cagemates. Enriched APPswe/PS1dE9 mice swam longer distances to find the platform in the MWM $(p<0.005$; Newman-Keuls post hoc test applied to simple main-effect ANOVA; $F_{(3,27)}=6.78 ; p<0.002$ ) (Fig. 1 $\left.a, b\right)$ and showed significantly lower preference for the correct quadrant than other enriched groups $(p<0.02$; Newman-Keuls post hoc test applied to significant-effect of genotype; $F_{(3,27)}=5.08$; $p<0.01$ ) (Fig. 1c). In the repeated-reversal version of this task, both APPswe and APPswe/PS1dE9 groups learned new platform locations more slowly than other enriched mice (genotype-bytrial interaction; $F_{(24,216)}=2.53 ; p<0.02$ ) (Fig. 1d). Enriched NTg and PS1dE9 mice required only one trial to significantly shorten their swim path to the platform (trial 1 vs trial 2 ; $p<$ 0.001; Newman-Keuls post hoc test applied to significant interaction) and reach an asymptotic level of performance (no other significant differences between trials 2-10; Newman-Keuls post hoc test), whereas APPswe and APPSwe/PS1dE9 mice were unable to demonstrate such one-trial learning (trial 1 vs trial $2 ; p>$ 0.3 ). These data indicate that enrichment did not completely resolve cognitive deficits in the $\mathrm{A} \beta$-overproducing mice and that the benefit provided by enrichment may be more limited in mice that have already accumulated amyloid plaques (APPswe/
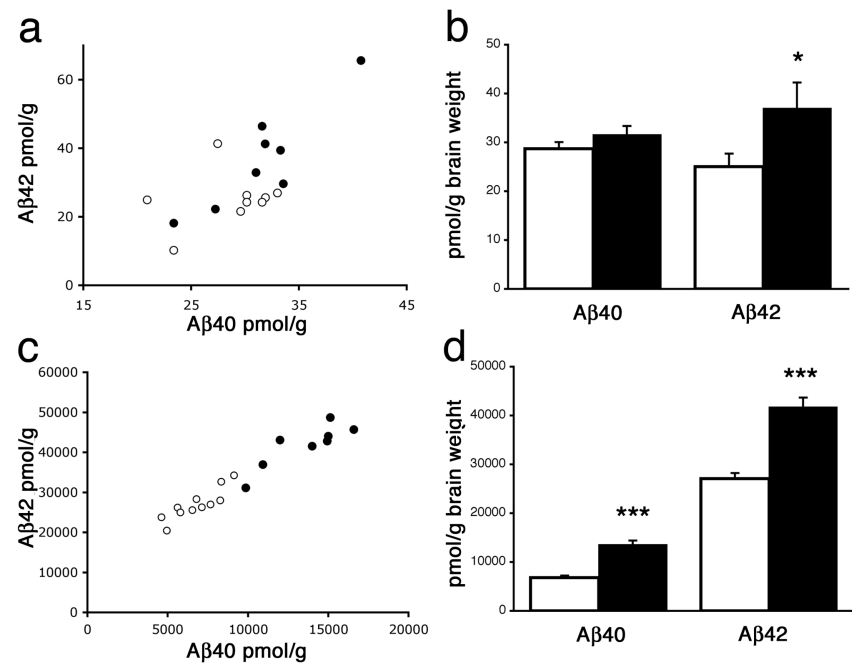

Figure 2. Hippocampal $A \beta$ levels are increased by enrichment. $\boldsymbol{a}-\boldsymbol{d}$, Sandwich ELISA was used to measure human $A \beta 40$ and $A \beta 42$ in formic acid extracts from enriched and standardhoused mice. $\boldsymbol{a}, \boldsymbol{b}$, Enriched APPswe single-transgenic animals display a specific increase in $\mathrm{A} \beta 42\left(F_{(1,14)}=4.57 ; p=0.05\right)$, with no significant change in $\mathrm{A} \beta 40\left(F_{(1,14)}=1.24 ; p<0.28\right.$; $n=9$ control; $n=8$ enriched). One outlier (data not shown), with $A \beta$ levels $>3$ SDs from the group mean, was removed from the control cohort before statistical analysis. $\boldsymbol{c}, \boldsymbol{d}$, Enrichment increases the level of both peptides in APPswe/PS1dE9 double-transgenic mice (A $\beta 42$ : $F_{(1,16)}=42.70, p<0.0001 ; A \beta 40: F_{(1,16)}=55.14, p<0.0001 ; n=11$ control; $n=8$ enriched). , Enriched; $\bigcirc$, control. Error bars represent mean \pm SEM. ${ }^{*} p=0.05 ;{ }^{* * *} p<$ 0.0005 .

PS1dE9). Nonetheless, by all measures, enrichment normalized the performance of both APPswe and APPswe/PS1dE9 mice to the level of standard-housed NTg mice (ANOVAs; $F=0.20-$ $1.88 ; p>0.19$ ) or better (APPswe mice; distance and time in the correct quadrant; $\left.F_{(1,15)}=6.02-8.84 ; p<0.03\right)$. Thus, cognitive deficits associated with the overproduction of APPswe and A $\beta$ can be significantly mitigated by environmental enrichment.

\section{$A \beta$ levels are increased by enrichment}

Recent work by Kamenetz et al. (2003) demonstrated that neuronal activity controls the formation and secretion of $\mathrm{A} \beta$ in vitro. To address whether synaptic enhancements associated with enrichment would lead to similar changes in $\mathrm{A} \beta$ levels in vivo, we analyzed peptide levels in single-transgenic APPswe mice that do not develop amyloid deposits until well after 12 months of age (Savonenko et al., 2003). Lacking a reservoir of insoluble A $\beta$, analysis of the single-transgenic animals allows for unequivocal determination of whether enrichment increases steady-state A $\beta$ levels in the brain. Quantitative ELISA (Kawarabayashi et al., 2001) revealed a specific increase in A $\beta 42$ from enriched APPswe mice compared with their standard-housed counterparts $(25.05$ $\mathrm{pmol} / \mathrm{g}$ control vs $36.95 \mathrm{pmol} / \mathrm{g}$ enriched; $F_{(1,14)}=4.57 ; p<$ 0.0507 ) (Fig. $2 b$ ). Analysis of hippocampal A $\beta$ levels in NTg mice confirmed that endogenous $\mathrm{A} \beta$ peptides (both $\mathrm{A} \beta 40$ and $\mathrm{A} \beta 42$ ) were also elevated by enrichment (see supplemental Fig. 1, available at www.jneurosci.org as supplemental material), demonstrating that the effects seen here are not specific to the transgene product. The effect of enrichment on $A \beta$ levels was magnified in the double-transgenic animals, in which extra $A \beta$ generated by enrichment was trapped in amyloid deposits. Compared with their standard-housed counterparts, enriched APPswe/PS1dE9 mice contained over $50 \%$ more A $\beta 42(27.04 \mathrm{nmol} / \mathrm{g}$ control vs $41.73 \mathrm{nmol} / \mathrm{g}$ enriched; $\left.F_{(1,16)}=42.70 ; p<0.0001\right)$ and twice the 
amount of $A \beta 40$ ( $6.80 \mathrm{nmol} / \mathrm{g}$ control vs $13.56 \mathrm{nmol} / \mathrm{g}$ enriched; $\left.F_{(1,16)}=55.15 ; p<0.0001\right)$ (Fig. $2 d$ ).

\section{Enrichment augments amyloid deposition in APPswe/PS1dE9 mice}

Silver staining of brain sections verified that at the ages tested, the cortex and hippocampus of only double-transgenic APPswe/ PS1dE9 mice contained amyloid plaques. Using nonbiased stereology, we estimated the fractional area of the hippocampus covered by neuritic plaques in each double-transgenic animal. Ubiquitin immunohistochemistry, which identifies plaques by the accumulation of this protein in dystrophic neurites, was chosen for stereology because it labels plaques with well defined borders and little nonspecific background as required for counting at high-power magnification. Consistent with the $\mathrm{A} \beta$ levels observed by ELISA (Fig. 2), the area occupied by neuritic plaques in enriched APPswe/PS1dE9 mice was 25\% greater than in standard-housed double-transgenic animals $(p<0.005)$ (Fig. 3). Importantly, the variance in neuritic plaque measures was no greater in the enriched mice than in standard-housed controls ( 1.415 vs $0.748 \% ; p=0.20$ ), suggesting that the wide range in neuritic plaque burden observed in our previous study of hybrid animals (Jankowsky et al., 2003) was influenced by genetic variation between individuals.

\section{Discussion}

In the present study, we show that environmental enrichment significantly improves several measures of cognitive performance in a mouse model of Alzheimer's disease. Transgenic animals overproducing APPswe and A $\beta$ kept in standard cages show substantial cognitive deficits in learning and memory compared with their NTg littermates. Exposure to complex housing before the onset of amyloid formation essentially eliminates these deficits in APPswe single-transgenic mice, consistent with a previous, more-limited study of similar mice (Arendash et al., 2004). We show that enrichment also enhances the performance of APPswe/ PS1dE9 mice with fulminant amyloid pathology, although their improvement was more limited. This behavioral recovery occurred in the enriched mice despite elevated steady-state levels of both endogenous- and transgene-derived $\mathrm{A} \beta$. We suggest that this outcome is consistent with the theory of cognitive reserve in human patients; the enriched mice were able to withstand a greater degree of pathological insult than their standard-housed counterparts with less cognitive decline. Our findings show that environmental factors can strongly modulate the pathological and behavioral progression of Alzheimer's in a mouse model that recapitulates these aspects of the disease.

Several decades of work have established that environmental enrichment can dramatically improve the cognitive abilities of healthy animals. Recent studies have shown that environmental stimulation also aids recovery from multiple forms of brain injury, including traumatic brain lesion (Will et al., 1977; Kolb and Gibb, 1991; Rose et al., 1993; van Praag et al., 2000, and references therein), status epilepticus (Faverjon et al., 2002; Rutten et al., 2002), and ischemia (Farrell et al., 2001; Dahlqvist et al., 2004; Gobbo and O'Mara, 2004). Enrichment also rectifies genetically induced cognitive deficits, such as those associated with hippocampal deletion of NMDA receptor 1 (Rampon et al., 2000). Even innate cognitive decline associated with aging is forestalled by exposure to enriched housing (Kubanis et al., 1982; Soffie et al., 1999; Frick and Fernandez, 2003). Our findings demonstrate that the benefits of environmental enrichment also extend to a mouse model for Alzheimer's disease, in which exposure to
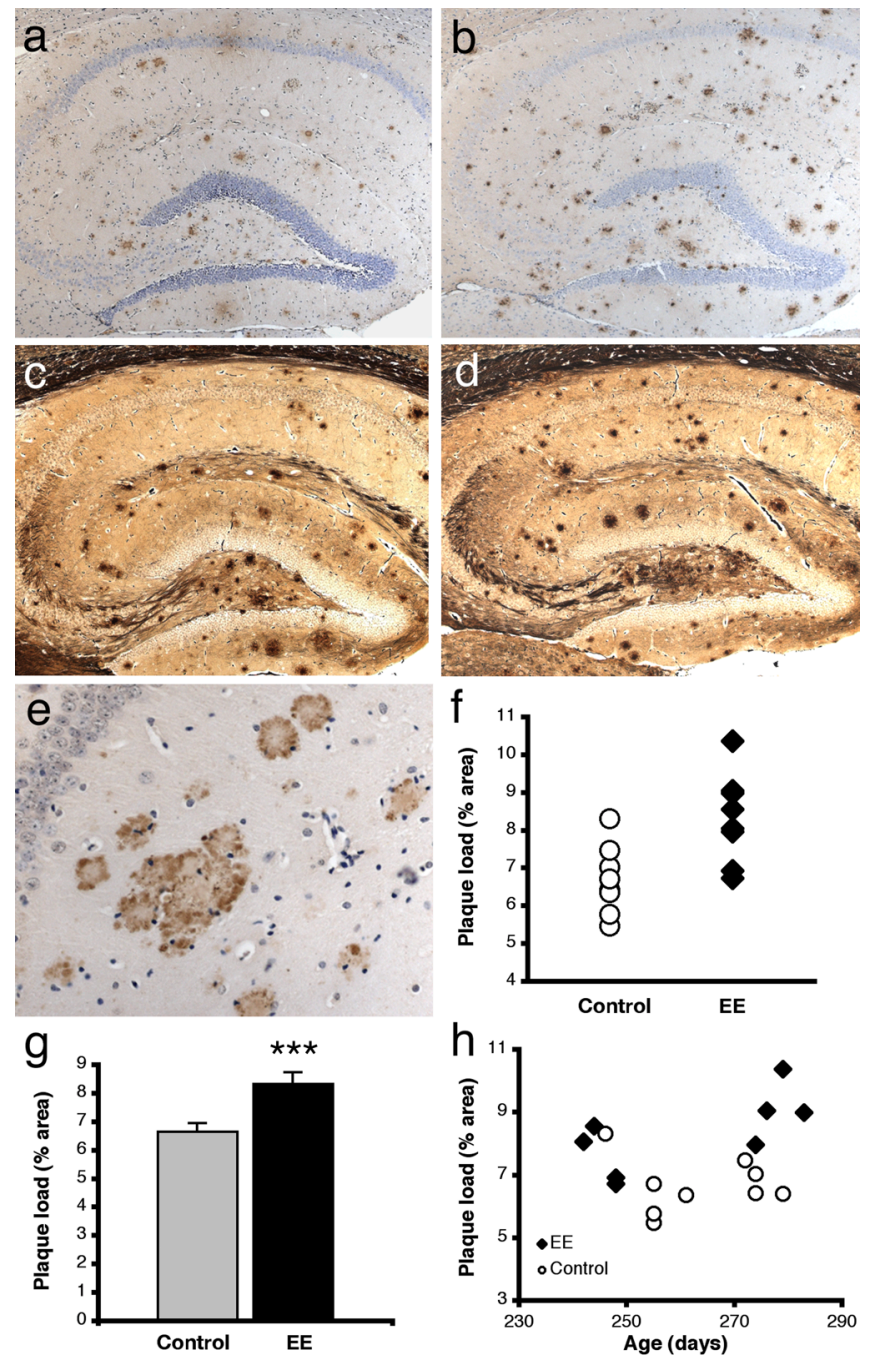

Figure 3. Enriched mice develop more amyloid than age-matched controls. $\boldsymbol{a}-\boldsymbol{d}$, Hippocampal sections stained for amyloid with $4 \mathrm{G8}(\boldsymbol{a}, \boldsymbol{b})$ or Hirano modified silver $(\boldsymbol{c}, \boldsymbol{d})$. These images were taken from an APPswe/PS1dE9 sibling pair separated after weaning into enriched $(\boldsymbol{b}, \boldsymbol{d})$ or standard $(\boldsymbol{a}, \boldsymbol{c})$ housing and killed at 9 months of age. Magnification, $100 \times$. e, Ubiquitin immunostaining, which labels dystrophic neurites surrounding dense-core deposits, was used to quantify amyloid burden by nonbiased stereology. Magnification, $400 \times$. $f$, Average plaque load (percentage of surface area occupied by ubiquitin-positive neuritic deposits) for each animal ( $n=11$ control; $n=8$ enriched). $\boldsymbol{g}$, Average plaque load in each cohort. Error bars represent mean \pm SEM. ${ }^{* * *} p<0.005$. $\boldsymbol{h}$, Plaque load versus age at harvest for each animal. Most enriched mice have higher amyloid burdens than controls of similar age. EE, Enriched.

environmental stimulation can abate the behavioral consequences of APPswe and/or $\mathrm{A} \beta$ overproduction.

In the course of this study, we discovered a previously unrecognized sexual dimorphism in the age at which cognitive deficits first appear in C57BL/6 congenic mice overexpressing APPswe. We find that standard-housed female APPswe mice show signs of cognitive decline by 8 months of age, long before the appearance of amyloid deposits. In contrast, previous studies of male animals from the same APPswe and PS1dE9 lines have found that cognitive deficits do not appear in male mice until much later, corresponding to the onset of amyloid deposition (Savonenko et al., 2005). We also note that in some transgenic mouse models (Callahan et al., 2001), including ours (Wang et al., 2003), female mice develop amyloid pathology earlier than males. Collectively, these data indicate that gender strongly influences the response to 
APPswe/A $\beta$ overproduction in transgenic models of Alzheimer's disease.

We find it intriguing that Lazarov et al. (2005) reported a much different pathological outcome after exposure to environmental stimulation in male mice from the same interbred lines used in the present study (C3-3 $\times$ S-9). In contrast to our findings, Lazarov et al. (2005) reported that periodic exposure to an enriched cage with unhindered access to an exercise wheel significantly reduced amyloid burden in male APPswe $\times$ PS1dE9 transgenic mice. Previous studies comparing the response to enrichment in male and female rats suggest that gender may influence the response to environmental stimulation (Wagner et al., 2002). With the enrichment paradigm used here, involving female mice, we have consistently observed increased neuritic plaque burden in response to enrichment. This outcome has occurred in two experiments using independent lines of APPswe/ PS1dE9 transgenic mice, one coinjected (line 57) (Jankowsky et al., 2003) and one interbred (lines C3-3 × S-9). Importantly, in the present study, we have generated closely age-matched animals that allowed our enriched cohorts to remain intact from start to finish. This change eliminates a potential source of social stress that was suggested as a mechanism for increased amyloid deposition observed in our previous study (Lazarov et al., 2005; Marx, 2005). Therefore, we believe that the divergent outcomes observed in male and female mice may represent a sexually dimorphic response to environmental stimulation.

In addition to the obvious gender differences, several other procedural aspects may have contributed to the distinct outcomes described here and by Lazarov et al. (2005). The enrichment housing used by Lazarov et al. (2005) emphasizes physical exercise: they provide one wheel for every two enriched mice. In this arrangement, the greatest benefit was found in the three animals that showed the highest levels of physical activity. In our paradigm, aerobic activity was not emphasized; animals shared access to two exercise wheels in each cage. Lazarov et al. (2005) proposed that in this setting, hierarchical competition for access to the wheels might have blunted the benefit of enrichment. However, both the number of animals in each enrichment cage (16) and the ratio of mice to exercise wheels (8:1) (as well as the cages themselves) were taken directly from the experiments of Kempermann et al. (1997) and van Praag et al. (1999), in which 12-14 mice share access to one wheel. Other significant differences between the two studies include continuous exposure to the enriched caging (including the dark phase of the day-night cycle when mice are normally most active) and more complex social interaction in our paradigm. Careful dissection of the individual and combined effects of exercise and social activity suggest that the greatest functional benefit is obtained when both are provided (Johansson and Ohlsson, 1996; Risedal et al., 2002). Thus, in addition to gender, experimental differences between our study and that of Lazarov et al. (2005) might also contribute to the contrasting outcomes. Collectively though, these two studies provide strong experimental evidence that mental and physical activity can modulate the expression of Alzheimer's-related pathological and cognitive abnormalities.

The mechanism by which $\mathrm{A} \beta$ levels increase in our mice after enrichment is not yet clear. Work by Kamenetz et al. (2003) has shown that synaptic activity can increase the production of $A \beta$ in cultured hippocampal neurons by enhancing $\beta$-APP processing by BACE1 ( $\beta$-site APP-cleaving enzyme). The environmental enrichment paradigm we used is known to enhance synaptic strength and connectivity (reviewed in van Praag et al., 2000). Thus, the elevated $A \beta$ levels we observed after enrichment may result from environmental stimulation of synaptic activity as seen by Kamenetz et al. (2003) after pharmacological stimulation. Alternatively, several groups have shown that production of endogenous APP can be increased by enrichment, which could be processed to generate a proportionate gain in $\mathrm{A} \beta$ (Huber et al., 1997; Teather et al., 2002).

Of course, steady-state levels of $\mathrm{A} \beta$ are a balance between production and clearance; $A \beta$ levels could also be increased by slowing degradation or by lowering sequestration of the peptide (Eckman et al., 2001; Iwata et al., 2001; Farris et al., 2003). Consistent with this mechanism, brain extracts from enriched male APPswe $\times$ PS1dE9 mice have almost twice the amount of neprilysin activity as their standard-housed counterparts (Lazarov et al., 2005). Because neprilysin activity was not examined in differentially housed nontransgenic animals, it is not clear whether the upregulation observed in APPswe $\times$ PS1dE9 mice is a general consequence of enrichment or an effect specific to animals with amyloid deposits. In the same study, male APPswe $\times$ PS1dE9 were also reported to show dramatic elevations in mRNA encoding transthyretin, a potentially protective factor thought to sequester A $\beta$ (Stein et al., 2004). However, this correlation was observed only in a subset of mice derived from one breeding pair ( $n=2$ standard housed; $n=5$ enriched) and could not be confirmed in the complete cohort. In the present study, we have used large cohorts of mice $(n=8$ per genotype enriched; $n=8-11$ per genotype standard housed) to demonstrate that environmental enrichment increases steady-state levels of both transgene-derived and endogenous A $\beta$. We believe increased APP processing and $\mathrm{A} \beta$ secretion associated with synaptic activity (Kamenetz et al., 2003) to be the most likely explanation for our findings, consistent with the well documented effects of enrichment on neuronal structure and function [see van Praag et al. (2000) for review of enrichment-associated synaptic changes and supplemental Fig. 2 (available at www.jneurosci.org as supplemental material) for further discussion of mechanism].

The amyloid hypothesis of Alzheimer's disease posits that excess $\mathrm{A} \beta$ initiates a pathological cascade leading to dementia (Hardy and Higgins, 1992; Hardy and Selkoe, 2002). Consistent with this hypothesis, transgenic mice overproducing APP and A $\beta$ have repeatedly shown cognitive deficits in tests of learning and memory (for review, see Janus and Westaway, 2001; Dodart et al., 2002; Higgins and Jacobsen, 2003). These animals harbor A $\beta$ levels severalfold over endogenous (300-500\%) but have been reared almost universally under impoverished conditions of standard colony cages. We suggest that the substantial improvement in brain function produced by enrichment outweighs the impairment caused by a relatively mild elevation in steady-state $\mathrm{A} \beta$ load (<50\%). By this interpretation, our results do not contradict the amyloid hypothesis but suggest that the progression from $A \beta$ pathology to dementia can be modified by environmental factors. This refinement to the amyloid hypothesis is implicit in the cognitive reserve theory, and several dozen epidemiological studies have demonstrated the influence of education, occupation, and lifestyle choices on the development of dementia (for review, see Stern, 2002; Scarmeas and Stern, 2003). Moreover, multiple studies from the clinical literature have documented patients with preserved cognitive function despite the presence of neuritic plaques and/or neurofibrillary tangles at levels normally diagnostic of Alzheimer's disease (Katzman et al., 1988; Dickson et al., 1992; Sparks et al., 1993, 1995, and references therein; Davis et al., 1999). Thus, the brain has the capacity to surmount significant insult and yet remain functionally intact.

Overall, these experiments indicate that environmental enrichment can substantially attenuate cognitive deficits associated 
with elevated levels of $\mathrm{A} \beta$ in APPswe and APPswe/PS1dE9 transgenic mice. Improvements were observed in multiple hippocampal-dependent tasks, indicating that enrichment had a strong impact on this key cognitive system. Perhaps most impressive were the cognitive improvements shown by APPswe/PS1dE9 animals despite enrichment-induced increases in amyloid pathology. These data suggest that environmental influences could be one mechanism behind the wide variation of disease onset and progression in the human Alzheimer's disease population and may explain the lack of correlation between amyloid pathology and cognitive symptoms in repeated clinical studies. Our study provides experimental evidence that even in the face of Alzheimer's-related pathological lesions, the function of the nervous system can be substantially influenced by environmental factors.

\section{References}

Andreasson KI, Savonenko A, Vidensky S, Goellner JJ, Zhang Y, Shaffer A, Kaufmann WE, Worley PF, Isakson P, Markowska AL (2001) Agedependent cognitive deficits and neuronal apoptosis in cyclooxygenase-2 transgenic mice. J Neurosci 21:8198-8209.

Arendash GW, King DL, Gordon MN, Morgan D, Hatcher JM, Hope CE, Diamond DM (2001) Progressive, age-related behavioral impairments in transgenic mice carrying both mutant amyloid precursor protein and presenilin-1 transgenes. Brain Res 891:42-53.

Arendash GW, Garcia MF, Costa DA, Cracchiolo JR, Wefes IM, Potter H (2004) Environmental enrichment improves cognition in aged Alzheimer's transgenic mice despite stable $\beta$-amyloid deposition. NeuroReport 15:1751-1754.

Banbury Conference on Genetic Background in Mice (1997) Mutant mice and neuroscience: recommendations concerning genetic background. Neuron 19:755-759.

Bonaiuto S, Rocca WA, Lippi A, Giannandrea E, Mele M, Cavarzeran F, Amaducci L (1995) Education and occupation as risk factors for dementia: a population-based case-control study. Neuroepidemiology 14:101-109.

Borchelt DR, Davis J, Fischer M, Lee MK, Slunt HH, Ratovitski T, Regard J, Copeland NG, Jenkins NA, Sisodia SS, Price DL (1996) A vector for expressing foreign genes in the brains and hearts of transgenic mice. Genet Anal 13:159-163.

Borchelt DR, Ratovitski T, van Lare J, Lee MK, Gonzales V, Jenkins NA, Copeland NG, Price DL, Sisodia SS (1997) Accelerated amyloid deposition in the brains of transgenic mice coexpressing mutant presenilin 1 and amyloid precursor proteins. Neuron 19:939-945.

Buckner RL (2004) Memory and executive function in aging and AD: multiple factors that cause decline and reserve factors that compensate. Neuron 44:195-208.

Callahan MJ, Lipinski WJ, Bian F, Durham RA, Pack A, Walker LC (2001) Augmented senile plaque load in aged female $\beta$-amyloid precursor protein-transgenic mice. Am J Pathol 158:1173-1177.

Chen G, Chen KS, Knox J, Inglis J, Bernard A, Martin SJ, Justice A, McConlogue L, Games D, Freedman SB, Morris RG (2000) A learning deficit related to age and $\beta$-amyloid plaques in a mouse model of Alzheimer's disease. Nature 408:975-979.

Dahlqvist P, Ronnback A, Bergstrom SA, Soderstrom I, Olsson T (2004) Environmental enrichment reverses learning impairment in the Morris water maze after focal cerebral ischemia in rats. Eur $\mathrm{J}$ Neurosci 19:2288-2298.

Davis DG, Schmitt FA, Wekstein DR, Markesbery WR (1999) Alzheimer neuropathologic alterations in aged cognitively normal subjects. J Neuropathol Exp Neurol 58:376-388.

Dickson DW, Crystal HA, Mattiace LA, Masur DM, Blau AD, Davies P, Yen SH, Aronson MK (1992) Identification of normal and pathological aging in prospectively studied nondemented elderly humans. Neurobiol Aging 13:179-189.

Dodart JC, Mathis C, Bales KR, Paul SM (2002) Does my mouse have Alzheimer's disease? Genes Brain Behav 1:142-155.

Duffy SN, Craddock KJ, Abel T, Nguyen PV (2001) Environmental enrichment modifies the PKA-dependence of hippocampal LTP and improves hippocampus-dependent memory. Learn Mem 8:26-34.
Eckman EA, Reed DK, Eckman CB (2001) Degradation of the Alzheimer's amyloid- $\beta$ peptide by endothelin-converting enzyme. J Biol Chem 276:24540-24548.

Escorihuela RM, Tobena A, Fernandez-Teruel A (1994) Environmental enrichment reverses the detrimental action of early inconsistent stimulation and increases the beneficial effects of postnatal handling on shuttlebox learning in adult rats. Behav Brain Res 61:169-173.

Farrell R, Evans S, Corbett D (2001) Environmental enrichment enhances recovery of function but exacerbates ischemic cell death. Neuroscience 107:585-592.

Farris W, Mansourian S, Chang Y, Lindsley L, Eckman EA, Frosch MP, Eckman CB, Tanzi RE, Selkoe DJ, Guenette S (2003) Insulin-degrading enzyme regulates the levels of insulin, amyloid $\beta$-protein, and the $\beta$-amyloid precursor protein intracellular domain in vivo. Proc Natl Acad Sci USA 100:4162-4167.

Faverjon S, Silveira DC, Fu DD, Cha BH, Akman C, Hu Y, Holmes GL (2002) Beneficial effects of enriched environment following status epilepticus in immature rats. Neurology 59:1356-1364.

Fratiglioni L, Paillard-Borg S, Winblad B (2004) An active and socially integrated lifestyle in late life might protect against dementia. Lancet Neurol 3:343-353.

Frick KM, Fernandez SM (2003) Enrichment enhances spatial memory and increases synaptophysin levels in aged female mice. Neurobiol Aging 24:615-626.

Frick KM, Baxter MG, Markowska AL, Olton DS, Price DL (1995) Agerelated spatial reference and working memory deficits assessed in the water maze. Neurobiol Aging 16:149-160.

Friedland RP (1993) Epidemiology, education, and the ecology of Alzheimer's disease. Neurology 43:246-249.

Friedland RP (1994) Epidemiology and neurobiology of the multiple determinants of Alzheimer's disease. Neurobiol Aging 15:239-241.

Friedland RP, Fritsch T, Smyth KA, Koss E, Lerner AJ, Chen CH, Petot GJ, Debanne SM (2001) Patients with Alzheimer's disease have reduced activities in midlife compared with healthy control-group members. Proc Natl Acad Sci USA 98:3440-3445.

Gobbo OL, O'Mara SM (2004) Impact of enriched-environment housing on brain-derived neurotrophic factor and on cognitive performance after a transient global ischemia. Behav Brain Res 152:231-241.

Hardy J, Selkoe DJ (2002) The amyloid hypothesis of Alzheimer's disease: progress and problems on the road to therapeutics. Science 297:353-356.

Hardy JA, Higgins GA (1992) Alzheimer's disease: the amyloid cascade hypothesis. Science 256:184-185.

Higgins GA, Jacobsen H (2003) Transgenic mouse models of Alzheimer's disease: phenotype and application. Behav Pharmacol 14:419-438.

Huber G, Bailly Y, Martin JR, Mariani J, Brugg B (1997) Synaptic $\beta$-amyloid precursor proteins increase with learning capacity in rats. Neuroscience 80:313-320.

Iwata N, Tsubuki S, Takaki Y, Shirotani K, Lu B, Gerard NP, Gerard C, Hama E, Lee HJ, Saido TC (2001) Metabolic regulation of brain A $\beta$ by neprilysin. Science 292:1550-1552.

Jankowsky JL, Xu G, Fromholt D, Gonzales V, Borchelt DR (2003) Environmental enrichment exacerbates amyloid plaque formation in a transgenic mouse model of Alzheimer disease. J Neuropathol Exp Neurol 62:1220-1227.

Jankowsky JL, Fadale DJ, Anderson J, Xu GM, Gonzales V, Jenkins NA, Copeland NG, Lee MK, Younkin LH, Wagner SL, Younkin SG, Borchelt DR (2004) Mutant presenilins specifically elevate the levels of the 42 residue $\beta$-amyloid peptide in vivo: evidence for augmentation of a 42 -specific $\gamma$-secretase. Hum Mol Genet 13:159-170.

Janus C, Westaway D (2001) Transgenic mouse models of Alzheimer's disease. Physiol Behav 73:873-886.

Johansson BB, Ohlsson AL (1996) Environment, social interaction, and physical activity as determinants of functional outcome after cerebral infarction in the rat. Exp Neurol 139:322-327.

Kamenetz F, Tomita T, Hsieh H, Seabrook G, Borchelt D, Iwatsubo T, Sisodia S, Malinow R (2003) APP processing and synaptic function. Neuron 37:925-937.

Katzman R (1993) Education and the prevalence of dementia and Alzheimer's disease. Neurology 43:13-20.

Katzman R, Terry R, DeTeresa R, Brown T, Davies P, Fuld P, Renbing X, Peck A (1988) Clinical, pathological, and neurochemical changes in demen- 
tia: a subgroup with preserved mental status and numerous neocortical plaques. Ann Neurol 23:138-144.

Kawarabayashi T, Younkin LH, Saido TC, Shoji M, Ashe KH, Younkin SG (2001) Age-dependent changes in brain, CSF, and plasma amyloid- $\beta$ protein in the $\operatorname{Tg} 2576$ transgenic mouse model of Alzheimer's disease. J Neurosci 21:372-381.

Kempermann G, Kuhn HG, Gage FH (1997) More hippocampal neurons in adult mice living in an enriched environment. Nature 386:493-495.

Kolb B, Gibb R (1991) Environmental enrichment and cortical injury: behavioral and anatomical consequences of frontal cortex lesions. Cereb Cortex 1:189-198.

Kubanis P, Zornetzer SF, Freund G (1982) Memory and postsynaptic cholinergic receptors in aging mice. Pharmacol Biochem Behav 17:313-322.

Lazarov O, Robinson J, Tang YP, Hairston IS, Korade-Mirnics Z, Lee VM, Hersh LB, Sapolsky RM, Mirnics K, Sisodia SS (2005) Environmental enrichment reduces $\mathrm{A} \beta$ levels and amyloid deposition in transgenic mice. Cell 120:701-713.

Lee MK, Borchelt DR, Kim G, Thinakaran G, Slunt HH, Ratovitski T, Martin LJ, Kittur A, Gandy S, Levey AI, Jenkins N, Copeland N, Price DL, Sisodia SS (1997) Hyperaccumulation of FAD-linked presenilin 1 variants in vivo. Nat Med 3:756-760.

Markowska AL, Long JM, Johnson CT, Olton DS (1993) Variable-interval probe test as a tool for repeated measurements of spatial memory in the water maze. Behav Neurosci 107:627-632.

Marx J (2005) Alzheimer's disease. Play and exercise protect mouse brain from amyloid buildup. Science 307:1547.

Morgan D, Diamond DM, Gottschall PE, Ugen KE, Dickey C, Hardy J, Duff K, Jantzen P, DiCarlo G, Wilcock D, Connor K, Hatcher J, Hope C, Gordon M, Arendash GW (2000) A $\beta$ peptide vaccination prevents memory loss in an animal model of Alzheimer's disease. Nature 408:982-985.

Morris R (1984) Developments of a water-maze procedure for studying spatial learning in the rat. J Neurosci Methods 11:47-60.

Morris RG (2001) Episodic-like memory in animals: psychological criteria, neural mechanisms and the value of episodic-like tasks to investigate animal models of neurodegenerative disease. Philos Trans R Soc Lond B Biol Sci 356:1453-1465.

Mortimer JA (1988) Do psychosocial risk factors contribute to Alzheimer's disease? In: Etiology of dementia of Alzheimer's type (Henderson AS, Henderson JH, eds), pp 39-52. New York: Wiley.

Mortimer JA (1997) Brain reserve and the clinical expression of Alzheimer's disease. Geriatrics 52 [Suppl 2]:S50-S53.

Nitsch RM, Farber SA, Growdon JH, Wurtman RJ (1993) Release of amyloid $\beta$-protein precursor derivatives by electrical depolarization of rat hippocampal slices. Proc Natl Acad Sci USA 90:5191-5193.

Park GA, Pappas BA, Murtha SM, Ally A (1992) Enriched environment primes forebrain choline acetyltransferase activity to respond to learning experience. Neurosci Lett 143:259-262.

Pope SK, Shue VM, Beck C (2003) Will a healthy lifestyle help prevent Alzheimer's disease? Annu Rev Public Health 24:111-132.

Rampon C, Tang YP, Goodhouse J, Shimizu E, Kyin M, Tsien JZ (2000) Enrichment induces structural changes and recovery from nonspatial memory deficits in CA1 NMDAR1-knockout mice. Nat Neurosci 3:238-244.

Risedal A, Mattsson B, Dahlqvist P, Nordborg C, Olsson T, Johansson BB (2002) Environmental influences on functional outcome after a cortical infarct in the rat. Brain Res Bull 58:315-321.

Rose FD, al-Khamees K, Davey MJ, Attree EA (1993) Environmental enrichment following brain damage: an aid to recovery or compensation? Behav Brain Res 56:93-100.

Rutten A, van Albada M, Silveira DC, Cha BH, Liu X, Hu YN, Cilio MR, Holmes GL (2002) Memory impairment following status epilepticus in immature rats: time-course and environmental effects. Eur J Neurosci 16:501-513.

Saari MJ, Armstrong JN, Nobrega JN, Pappas BA, Coscina DV (1990) Neonatal 6-hydroxydopamine alters the behavior of enriched-impoverished rats in a novel test environment. Behav Neurosci 104:430-437.

Savonenko AV, Xu GM, Price DL, Borchelt DR, Markowska AL (2003) Normal cognitive behavior in two distinct congenic lines of transgenic mice hyperexpressing mutant APPswe. Neurobiol Dis 12:194-211.
Savonenko A, Xu GM, Melnikova T, Morton JL, Gonzales V, Wong MP, Price DL, Tang F, Markowska AL, Borchelt DR (2005) Episodic-like memory deficits in the APPswe/PS1dE9 mouse model of Alzheimer's disease: relationships to $\beta$-amyloid deposition and neurotransmitter abnormalities. Neurobiol Dis 18:602-617.

Scarmeas N, Stern Y (2003) Cognitive reserve and lifestyle. J Clin Exp Neuropsychol 25:625-633.

Scarmeas N, Stern Y (2004) Cognitive reserve: implications for diagnosis and prevention of Alzheimer's disease. Curr Neurol Neurosci Rep 4:374-380.

Soffie M, Hahn K, Terao E, Eclancher F (1999) Behavioural and glial changes in old rats following environmental enrichment. Behav Brain Res 101:37-49.

Sparks DL, Liu H, Scheff SW, Coyne CM, Hunsaker III JC (1993) Temporal sequence of plaque formation in the cerebral cortex of non-demented individuals. J Neuropathol Exp Neurol 52:135-142.

Sparks DL, Scheff SW, Liu H, Landers TM, Coyne CM, Hunsaker III JC (1995) Increased incidence of neurofibrillary tangles (NFT) in nondemented individuals with hypertension. J Neurol Sci 131:162-169.

Stein TD, Anders NJ, DeCarli C, Chan SL, Mattson MP, Johnson JA (2004) Neutralization of transthyretin reverses the neuroprotective effects of secreted amyloid precursor protein (APP) in APPSW mice resulting in tau phosphorylation and loss of hippocampal neurons: support for the amyloid hypothesis. J Neurosci 24:7707-7717.

Stern Y (2002) What is cognitive reserve? Theory and research application of the reserve concept. J Int Neuropsychol Soc 8:448-460.

Stern Y, Gurland B, Tatemichi TK, Tang MX, Wilder D, Mayeux R (1994) Influence of education and occupation on the incidence of Alzheimer's disease. JAMA 271:1004-1010.

Teather LA, Magnusson JE, Chow CM, Wurtman RJ (2002) Environmental conditions influence hippocampus-dependent behaviours and brain levels of amyloid precursor protein in rats. Eur J Neurosci 16:2405-2415.

Terry R, Katzman RD, Bick KL, Sisodia SS, eds (1999) Alzheimer disease, Ed 2. Philadelphia: Lippincott Williams and Wilkins.

van Dellen A, Blakemore C, Deacon R, York D, Hannan AJ (2000) Delaying the onset of Huntington's in mice. Nature 404:721-722.

van Praag H, Kempermann G, Gage FH (1999) Running increases cell proliferation and neurogenesis in the adult mouse dentate gyrus. Nat Neurosci 2:266-270.

van Praag H, Kempermann G, Gage FH (2000) Neural consequences of environmental enrichment. Nat Rev Neurosci 1:191-198.

Wagner AK, Kline AE, Sokoloski J, Zafonte RD, Capulong E, Dixon CE (2002) Intervention with environmental enrichment after experimental brain trauma enhances cognitive recovery in male but not female rats. Neurosci Lett 334:165-168.

Wainwright PE, Levesque S, Krempulec L, Bulman-Fleming B, McCutcheon Dw (1993) Effects of environmental enrichment on cortical depth and Morris-maze performance in B6D2F2 mice exposed prenatally to ethanol. Neurotoxicol Teratol 15:11-20.

Wang J, Tanila H, Puolivali J, Kadish I, van Groen T (2003) Gender differences in the amount and deposition of amyloid- $\beta$ in APPswe and PS1 double transgenic mice. Neurobiol Dis 14:318-327.

White L, Katzman R, Losonczy K, Salive M, Wallace R, Berkman L, Taylor J, Fillenbaum G, Havlik R (1994) Association of education with incidence of cognitive impairment in three established populations for epidemiologic studies of the elderly. J Clin Epidemiol 47:363-374.

Will BE, Rosenzweig MR, Bennett EL, Hebert M, Morimoto H (1977) Relatively brief environmental enrichment aids recovery of learning capacity and alters brain measures after postweaning brain lesions in rats. J Comp Physiol Psychol 91:33-50.

Winocur G, Greenwood CE (1999) The effects of high fat diets and environmental influences on cognitive performance in rats. Behav Brain Res 101:153-161.

Woodcock EA, Richardson R (2000) Effects of environmental enrichment on rate of contextual processing and discriminative ability in adult rats. Neurobiol Learn Mem 73:1-10.

Zhang MY, Katzman R, Salmon D, Jin H, Cai GJ, Wang ZY, Qu GY, Grant I, Yu E, Levy P, Klauber MR, Liu WT (1990) The prevalence of dementia and Alzheimer's disease in Shanghai, China: impact of age, gender, and education. Ann Neurol 27:428-437. 